\title{
HUMAN HEALTH IS A FACTOR IN CREATING A HEALTHY LIFESTYLE ENVIRONMENT IN SOCIETY
}

\author{
G.Tulepova ${ }^{1}$ \\ ${ }^{\text {I}}$ Teacher of Nukus State Pedagogical Institute
}

\begin{abstract}
It is well known that human health is the greatest social wealth. And the health of a nation is naturally addressed through a culture of healthy living. Therefore, the formation of a healthy generation today is one of the most important tasks facing humanity. This includes, first of all, the formation of a healthy lifestyle, the creation of various living conditions, the establishment of the material basis for the upbringing of a healthy generation, ie economic and financial support from the state.
\end{abstract}

Key words: healthy life, happy life, physical fitness, pedagogical process.

\section{Introduction}

It is impossible to think about a healthy life, a healthy mind, a prosperous and happy life without ensuring people's health.

The formation of a healthy lifestyle among young people is the main goal of the state youth policy in the Republic of Uzbekistan. During the years of independence, on the basis of the idea of a harmoniously developed generation, the socio-legal basis of the problem of this state policy has been created.

Constitution of the Republic of Uzbekistan, Laws "On Education", "On National Training Program", "On State Youth Policy", "On Public Health", "On Prevention of Human Immunodeficiency Virus Infection (HIV)", "On social protection of the disabled", "On development of physical culture and sports", "On guarantees of children's rights", "On prevention of juvenile delinquency and delinquency", "On restriction of distribution and consumption of alcohol and tobacco products", "On social protection of the population "On strengthening the targeted support of vulnerable groups."

In particular, the President of the Republic of Uzbekistan signed a decree on December 26, 2008 "On additional measures to increase the effectiveness of combating the spread of HIV in the Republic of Uzbekistan." No. PQ-1023 "On additional measures to protect the health of mothers and children, the formation of a healthy generation"

\section{Main part}

Resolution No. PQ-1096 "On the Program of Measures to Strengthen and Increase the Effectiveness of Work on Strengthening the Reproductive Health of the Population, Healthy Childbirth, Raising a Physically and Spiritually Harmonious Generation for 2009-2013" indicates that special attention is paid to the field. These documents:

realization of the rights and freedoms of youth;

formation of a culture of healthy living;

creation of a strict system of their social protection;

to increase the social activity of young people, to ensure the wider realization of their interests;

creation of conditions and opportunities for people with disabilities to live a full life, to take an active part in the socio-economic and political life of society;

providing medical care to young people who have been disabled since childhood or who need help as a result of life-threatening injuries;

formation of a culture of healthy living of young people through the development of physical culture and sports;

delivery of various micronutrients that affect the birth of healthy children;

ecology, scientific approach to the impact of the environment on youth STM; people;

prevention and combating harmful habits that affect the spiritual and physical development of young

focused on juvenile delinquency and crime prevention.

The most important task of physical education is to maintain and improve human health. In this regard, human health should be the object of medical and pedagogical research. It is important to note here that physical development, body structure, functioning of the cardiovascular system, physical fitness and physical condition are all components of health. Therefore, in order to manage a person and achieve his physical maturity, it is necessary to comprehensively assess physical fitness on a number of indicators (physical development and body structure, physical and functional fitness).

It should be noted that in order to individualize the process of achieving physical perfection, it is necessary to know the personal characteristics of the person. Various psychological tests (Kettel, Eisenk, Strelyau, Peysakhov-Gabdreeva tests) can be used for this purpose. Comprehensive accounting of the data of medical pedagogical and psychological research allows to determine the types and methods of healthimproving physical education to obtain accurate information about the physical condition. 
The complex data used in pedagogical research, medical examinations and information support methods help to solve the following problems:

1. Determining a person's physical condition.

2. Assessment of physical development, physical and functional readiness.

3. Determining the dynamics of human physical maturity.

4. Identify effective ways to improve.

5. To study the system of planning the process of reaching maturity.

6. Individualization of achieving physical maturity.

7. Develop a need for independent, regular, practical exercise.

8. Teaching self-control techniques, etc.

Considerations about human physical maturity should be considered in relation to pedagogical, medicalbiological and psychological indicators.

\section{Conclusion}

In short, while physical maturity is the result of a pedagogical process that shapes a person through the means of physical education, the formation of a healthy lifestyle in a person is to nurture high working capacity, maintain and strengthen health, equip them with the knowledge and skills needed to lead a healthy lifestyle.

\section{References}

1.Basov A.V. wa boshқ. Lifestyle and our health. Yaroslavl: Top. - Volzh. Book. Publishing house. $1989 .--127$ p.

2.Mo'minova F. Factors in the formation of healthy lifestyle skills in students // School and life №7, 2002. - 20-21 p.

3.Jienbekovna, T. A. (2019). COMPARATIVE ANALYSES OF TEACHERS'TRAINING SYSTEM OF FOREIGN COUNTRIES. European Journal of Research and Reflection in Educational Sciences Vol, 7(12).

4.Irgashevich, D. A. (2019). Development of national network and corporate networks (in the case of Tas-IX network). International Journal of Human Computing Studies, 1(1), 1-5.

5.Irgashevich, D. A. (2020). Development of national network (tas-ix). ACADEMICIA: An International Multidisciplinary Research Journal, 10(5), 144-151. 